\title{
Coupling Coordinative Degree Analysis of Cultural and Creative Industry and Tourism Industry under the Background of Cultural and Tourism Integration
}

\author{
Chunfeng Li, Peng Ju* \\ Shenzhen Tourism College of Jinan University, Shenzhen, China \\ Email:1_cf47407@163.com, *jupeng@sz.jnu.edu.cn
}

How to cite this paper: Li, C.F. and Ju, P. (2020) Coupling Coordinative Degree Analysis of Cultural and Creative Industry and Tourism Industry under the Background of Cultural and Tourism Integration. Journal of Service Science and Management, 13, 97-117.

https://doi.org/10.4236/jssm.2020.131007

Received: December 31, 2019

Accepted: February 4, 2020

Published: February 7, 2020

Copyright $\odot 2020$ by author(s) and Scientific Research Publishing Inc. This work is licensed under the Creative Commons Attribution International License (CC BY 4.0).

http://creativecommons.org/licenses/by/4.0/

(c) (i) Open Access

\begin{abstract}
Under the background of cultural and tourism integration, this paper sorts out the coupling and coordination mechanism of cultural and creative industries and tourism industries, and then takes Shenzhen as the research area to explore the coupling and coordination development of these two industries from 2008 to 2017 by using the coupling coordination model. Meanwhile, it applies the grey correlation model to further study the main driving factors of the coupling and coordination of these two industries. Conclusions are drawn as follows: cultural and creative industries and tourism industries develop in an interactive and coupling way, and the former empowers the latter's creativity while the latter provides platform support for the former. The comprehensive development level of the two industries is rising rapidly and in good condition, but the tourism industry began to decline in 2016 and has been overtaken by cultural and creative industries. There is a significant coupling development relationship between these two industries, and the degree of coupling coordination still has possibility for improvement. The main driving forces for the coupling and coordination of the two industries are the added value of cultural and creative industries as a proportion of the city's GDP and tourism foreign exchange income, followed by the number of cultural and creative industries parks (bases), travel agencies and other industrial factors and employees.
\end{abstract}

\section{Keywords}

Cultural and Creative Industry, Tourism Industry, Coupling Coordination Degree, Grey Correlation, Shenzhen 


\section{Introduction}

In recent years, as a rising industry chased after by cities, cultural and creative industry has become the focus of China's economic development, featuring innovation and permeability [1]. Its integration with other industries has generated a number of emerging industrial and product forms, injecting vitality into the economic development for various regions. Taking advantages of the policy of cultural and tourism integration, cultural and creative industry and tourism industry are interactively developing for mutual promotion and influence. In terms of economy, cultural and creative industry promotes the transformation and upgrading of tourism industry and the growth of tourism economy [2] while tourism industry extends the industrial chain of cultural and creative industry and expands its market. In terms of culture, the cultural and creative industry provides technical support and transmission of cultural creativity for the tourism industry, which can not only effectively protect and pass on cultural creativity, but also promote the exchange. To accelerate the cultural creativity development and integration, relevant governmental departments have issued Guidance on Promoting Culture and Tourism and Advancing the Cultural Creativity and Design services and the Related Industrial Integration development, necessitating improving cultural creativity improvement and overall strength, cultural creativity promotion and relevant industries' integration; enhance tourism quality by cultural creative and expand its consumption by tourism. Thus, by integrating the advantages of both industries, the expansion of industries, as well mutual promotion and development are realized.

Cultural and creative industry researches, carried out by domestic scholars relatively late [3], are about theories and basic practice, with no unified definition of the concepts of cultural industry and cultural and creative industry. Worse still, "new concepts are created from nowhere" and the concepts of cultural industry are replaced with cultural and creative industry. In fact, the cultural creative industry, with creation, invention and innovation as the basic means and cultural content, creative achievements and intellectual property rights as its core value, taking high-new technology as the important support, provide the social public with cultural products and services, leading the cultural industry development and consumption trend of emerging industries [4]. Cultural industry is a collection of cultural products for public and culture related products production activities [5]. Cultural and creative industry originates from cultural industry [6]. The main difference between the two is that the former lays more emphasis on innovation and technology, while the latter is the core background of the former's development [7].

At present, guided by the policy of cultural and tourism integration, domestic scholars focus on the coupling of cultural industry and tourism industry, mostly by the coupling quantitative method of panel data [8], grey system analysis theory [9] and coupling coordination degree model [10] [11]. A large blank still remains in research of the coupled development of tourism industry and cultural 
and creative industry, but some basic achievements are realized in integrated process and patterns of these two industries. From the point of formats, Tang Yujun pointed out that integration of the tourism industry and cultural creative industry consists of three stages, respectively the agglomeration stage, the development stage (transition stage) of cultural and creative related service industry and the multi-functional development stage of tourism and leisure [12]. With the industrial value chain, Zhang Jian elaborates the integration of cultural and creative industry and tourism industry [13]. Taking Chengdu as a case, Zou Yun explored the diversified integration mode of "penetration, restructuring and extension" between tourism and cultural and creative industry [1]. Yuan Jun et al. applied the content analysis method of network comments to preliminarily explore the integration effect of cultural and creative industrial parks and tourism industry in different regions of China [14]. Industrial integration is an important manifestation of industrial coupling [15]. The researches on the integration of domestic cultural and creative industry and tourism industry have laid a solid theoretical foundation for the research on the coupling of the two industries. Meanwhile, scholars at home and abroad have also explored the integration of certain cultural and creative industry with tourism, such as animation industry [16], performing arts industry [17] [18] [19] and online game industry [20], further providing theoretical reference for the coupling of these two industries. Moreover, scholars at home and abroad begin their exploration in the close relationship between mutual interaction of these two industries. For example, Yin Yimei believes that the development of cultural and creative industry in ethnic regions can not only protect ethnic cultural resources but also promote the development of local tourism economy [21]. Kostopoulou pointed out that tourism industry development driven by creativity has an important impact on regional planning and cultural identity [22], indicating the direction for the development of cultural and creative industry and tourism industry. To sum up, with the promotion and implementation of policy of cultural and tourism integration, domestic scholars still focus on coupled cultural industry and tourism industry. Some scholars begin to study integration development of cultural and creative industry and tourism, pointing out that there exists interactive coupling basis in them, yet there is still a lack of mechanism analysis and coupling research on the interaction and coordinated development of these two industries. Moreover, before that, most scholars have used qualitative research methods to explore the interaction between the two, but quantitative empirical research are still in absence.

With significant cultural and creative industry advantages and developed tourism economy, Shenzhen typically represents the study of cultural and creative industry and coupled development. Relevant government departments have issued The 13th five-year Plan of Shenzhen's Tourism Development, plans for the establishment of national all-area tourism demonstration zones, and $O p$ i- $^{-}$ nions of CPC Central Committee and the State Council on Supporting the Construction of a Socialist Pilot Demonstration Zone with Chinese characteristics in 
Shenzhen, pointing out that we should promote the development of tourism + cultural creativity, build a modern and international innovative city, and create a favorable policy environment for coupling coordinative development of cultural and creative industry and tourism industry. In view of this, taking Shenzhen as a case, this paper uses the coupling and coordinative model to analyze 2008-2017 interactive coordination of cultural and creative industry and tourism industry, combined with the grey correlation model, exploring the main driving force factors of the two industries, to provide their future development layout with theoretical reference. The purposes of this study are: 1) to explore the dynamic trend of the coupling development of cultural and creative industry and tourism industry; 2) to determine the indicators with strong correlation degree of coupling coordination degree between cultural and creative industry and tourism industry; 3 ) to provide reference for the coordinated development of cultural and creative industry and tourism industry in macro policy-making.

\section{Analysis on the Coupled Development Mechanism of Cultural and Creative Industry and Tourism Industry}

Up to now, few papers have studied the coupling development of cultural and creative industry and tourism industry. Based on previous studies, so this paper has sorted out the coupling mechanism of cultural and creative industry and tourism industry, laying a theoretical foundation for the subsequent coupling empirical research of this study and pointing out the direction for the index selection of these two industrial systems.

The interaction and coupled development of cultural and creative industry and tourism industry is inevitable. On the one hand, cultural and creative industry, based on "culture" and centered on "creativity" [23], penetrates into various fields and branches of the tourism industry, providing creative energy for the tourism industry, and generating new products, new businesses, new markets, new technologies and new space [1]. On the other hand, the tourism industry features experience, participation and industry relevance, interacting with "clothing, food, travel, entertainment and other industries", also playing important role for emerging industries such as cultural creative industry, and ultimately, the interactive and coordinative development of cultural and creative industry and tourism industry will be realized. The coupled development mechanism of cultural and creative industry and tourism industry (Figure 1).

The essence of coupled development of tourism industry and cultural creative industry explains as the process of the two systems permeating each other and realizing the added value of the industry [2]. Tourism industry excavates cultural connotation of cultural and creative industry and provides "creative economization" platform. From the perspective of culture, taking the tourism industry as the carrier, the cultural and creative industry transmits cultural creativity to the outside world and transports cultural creativity to the inside with the benefit of the huge tourism market, aiming to promote the cultural exchange and dissemination of the cultural creativity industry. The combination of cultural and 


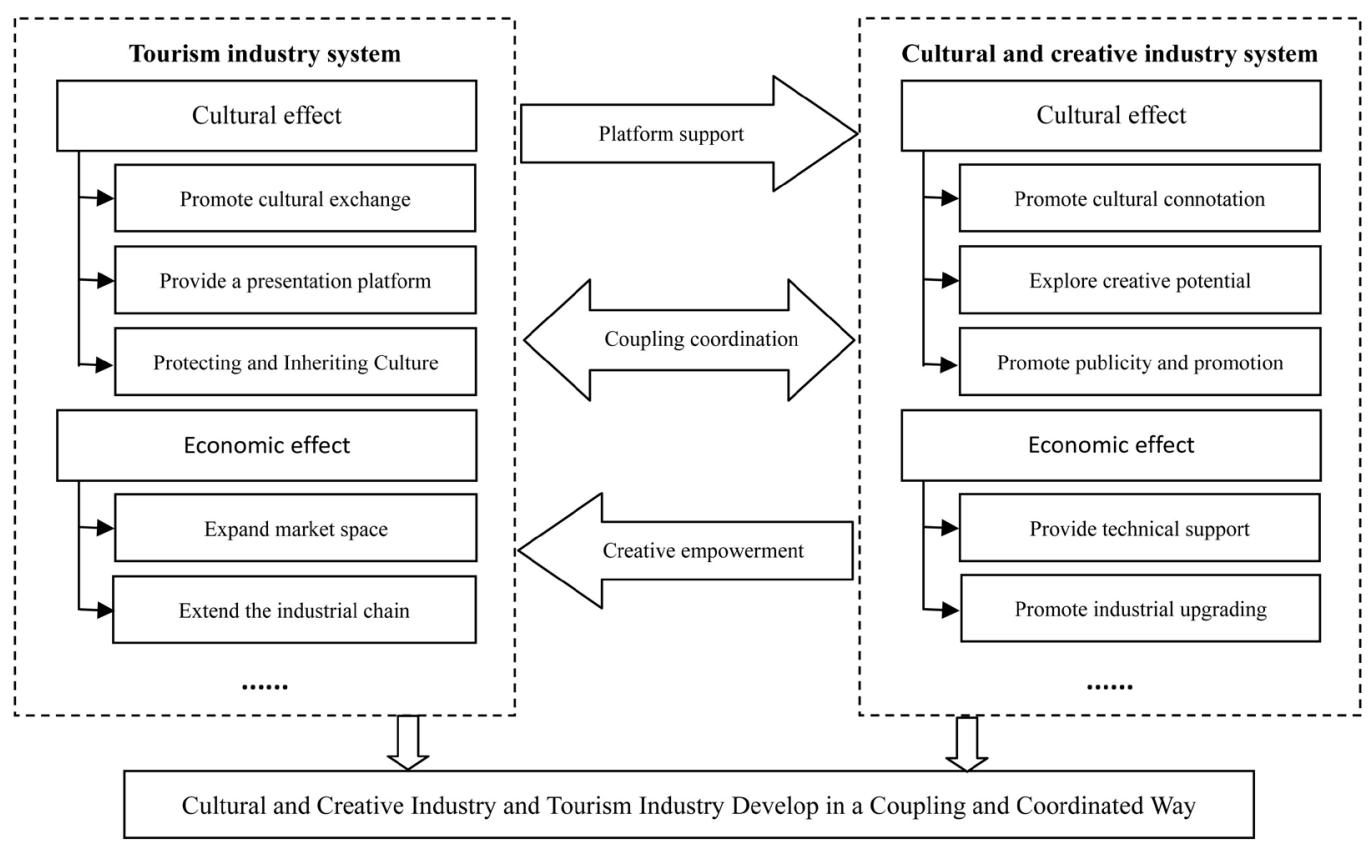

Figure 1. Relationship of coupling coordination between tourism and cultural and creative industry.

creative elements and tourism can attract tourists to experience the creation process of cultural and creative products, guides tourists to strengthen cultural and creative products through word-of-mouth communication, and provide a display platform for cultural and creative industry [24]. From an economic perspective, on the one hand, with an economic attribute, tourism injects vitality into the cultural and creative industry through resource sharing and market sharing, turning creativity into productivity, and creative products into tourism creative services and commodities, thus greatly expanding the market space of the cultural and creative industry. On the other hand, the extension of the cultural and creative industry chain and the tourism industry enables the creation, production and sales of the cultural and creative industry chain to generate diversified tourism creative products and services and provide consumers with unique tourism experience.

Cultural and creative industry enriches the connotation and extension of the tourism industry and realizes "economic creativity". From the cultural perspective, first of all, cultural creativity integrated into the tourism development can not only meet people's demand for personalized in-depth tourism experience, but also increase the cultural added value of tourism products, promoting the sustainable development of the tourism industry. Secondly, the interaction and coordination between the cultural and creative industry and the tourism industry has the potential to tap the creative potential of the latter, innovating the contents of tourism products. In addition, with the brand influence of cultural and creative tourism products, the tourism industry can gain more publicity and promotion channel, thus gain higher popularity. From an economic perspective, the cultural and creative industry provides technical support for the tourism development, conducive to new tourism products in line with market demand and 
social development. Cultural and creative industry also integrates knowledge, science, technology, capital and other innovation elements into the tourism industry [25], contributing to upgrading and transformation of the tourism industry and ultimately for the purpose of new normal-building a brand in the improvement of quality and efficiency, creating value in market innovation and expanding the space in the integration of the system [26].

\section{Research Objects, Methods and Data Sources}

\subsection{Research Objects}

Shenzhen, located in the Southern Guangdong province, is the central city of the Guangdong-Hong Kong-Macao Greater Bay Area, playing a leading role in economy and innovation. Moreover, it is advantageous on geographical conditions by adjacent to Hong Kong and Macao. It is an important hub linking Hong Kong, Macao and other cities in the bay area. Shenzhen, covers an area of 1997.47 square kilometers among which 1145 square kilometers of ocean area and $260 \mathrm{~km}$ long coastline. As of late 2018, with population of 13.0266 million and GDP topped 2.4 trillion yuan it ranked top 5 Asian cities for economic aggregate [27].

Since Shenzhen formulated the strategy of "building the city by culture" in 2003, the average annual growth rate of Shenzhen's cultural and creative industry has reached up to $25 \%$, ranking top among the Chinese large and medium-sized cities [4]. In 2010, Shenzhen Municipal Party Committee and Municipal Government proposed to make the cultural and creative industry in Shenzhen the fourth largest strategic emerging industry. At the same time, on the basis of hi-tech, finance, and coastal tourism, it decides to dig, integrate and link the related industry resources so as to form new pattern of industrial development such as "culture + technology", "culture + finance", "culture + tourism", which creates a good environment for the coupled development of cultural and creative industry and tourism industry. The development levels of Shenzhen's cultural and creative industry and tourism industry have been the top of China for many years (Table 1) [28] [29].

Table 1. Statistical information of cultural and creative industry and tourism industry in Shenzhen by 2018.

\begin{tabular}{|c|c|c|c|c|c|c|c|}
\hline \multicolumn{8}{|c|}{ Cultural and Creative Industry } \\
\hline Enterprises & $\begin{array}{c}\text { Scaled } \\
\text { enterprises }\end{array}$ & $\begin{array}{c}\text { Listed } \\
\text { enterprises }\end{array}$ & Employees & $\begin{array}{l}\text { National cultural } \\
\text { industry platforms }\end{array}$ & $\begin{array}{l}\text { National cultural } \\
\text { industry parks }\end{array}$ & $\begin{array}{c}\text { National } \\
\text { industrial bases }\end{array}$ & $\begin{array}{l}\text { Cultural and creative } \\
\text { industry parks (bases) scaled } \\
\text { at the municipal level or above }\end{array}$ \\
\hline 50,000 & 3155 & 40 & 900,000 & 4 & 1 & 12 & 53 \\
\hline \multicolumn{8}{|c|}{ Tourism Industry } \\
\hline \multicolumn{4}{|c|}{$\begin{array}{l}\text { Total revenue of Shenzhen's tourism industry } \\
\text { ( } 0.1 \text { billion yuan })\end{array}$} & \multicolumn{2}{|c|}{ Year-on-year growth rate (\%) } & \multicolumn{2}{|c|}{ Accounts for the proportion of Guangdong's (\%) } \\
\hline \multicolumn{4}{|c|}{160,910} & \multicolumn{2}{|c|}{8.32} & \multicolumn{2}{|r|}{11.84} \\
\hline \multicolumn{4}{|c|}{ Domestic and overseas tourists (million) } & \multicolumn{2}{|c|}{ Year-on-year growth rate (\%) } & \multicolumn{2}{|c|}{ Accounts for the proportion of Guangdong's (\%) } \\
\hline \multicolumn{4}{|c|}{139.3238} & \multicolumn{2}{|c|}{5.97} & \multicolumn{2}{|r|}{28.41} \\
\hline
\end{tabular}




\subsection{Research Methods}

\subsubsection{Index System}

The systems of both cultural and creative industry and tourism industry are complex, so there are several indexes selected for comprehensive evaluation. The construction of the index system adheres to three principles: first, the relevance. Starting from the concepts of cultural and creative industry and tourism industry, the paper selects indexes that can reflect the development level and integration of the two industries. Second, accessibility. Data are collected from statistical yearbooks, official government websites or news reports. Thirdly, scientificity. The establishment of the index system combines the frequency statistics method and the expert consultation, and integrates the previous research results and expert opinions to enhance its reliability and validity.

There is a natural coupled relationship between Cultural creative industry and tourism industry, though the elements interact within the system, there is no linear relationship [30]. Combined with the connotation and characteristics of the two industries, and follow the principles of constructing index system, through the frequency statistics, theoretical analysis and expert consultation, the indexes for evaluation are selected. Firstly, frequency statistics are conducted by selecting a decade's (2009-2019) articles with high frequency references and related to the evaluation index system of cultural and creative industry and tourism industry from CNKI database, including 10 articles on cultural and creative industry and 20 articles on tourism industry. Secondly, the index system is established according to the definition and connotation of the two industries. Finally, $10 \mathrm{ex}-$ perts in related fields are consulted and the evaluation index system is further adjusted according to the availability of data. In this system (Table 2), the index system of cultural and creative industry includes 19 items such as added value, proportion of added value accounts for the whole GDP, growth rate of added value, total import and export of high-tech products, and number of cultural and creative industrial parks (bases). The indexes system of tourism industry includes 16 items such as domestic tourism income, foreign exchange income of tourism, total income of tourism, proportion of total tourism income accounts for the whole GDP, proportion of total income of tourism accounts for the three major industries' output value, etc.

\subsubsection{Data Processing}

The index weight $w_{i j}$ is calculated by the relatively objective information entropy assignment method, which is based on the original information of the objective environment and determines the index weight by analyzing the degree of correlation between indicators and the information provided by each indicator, avoiding certain subjective errors [31] [32]. Set $x_{i j}$ as the original value $(i=1,2, \cdots, m$; $j=1,2, \cdots, n)$ of the $j$ index in year $i, x_{i j}^{\prime}$ is the value after normalization. The final calculation results of each index weight of cultural and creative industry and tourism industry system are shown in Table 2 . The specific calculation steps are as follows: 
Table 2. Index system and weight of coupled and coordinative system between cultural and creative industry and tourism industry.

\begin{tabular}{|c|c|c|c|c|c|c|}
\hline System & Primary index & Secondary index & Units & Weight & Quanlity & Data sources \\
\hline & \multirow{4}{*}{ Scales } & $\begin{array}{l}\text { C1 Added value of cultural and creative } \\
\text { industry }\end{array}$ & 0.1 billion yuan & 0.8279 & + & $\begin{array}{c}\text { Shenzhen Statistical } \\
\text { Yearbook }\end{array}$ \\
\hline & & $\begin{array}{l}\text { C2 Added value of cultural and creative } \\
\text { industries accounts for the proportion of the } \\
\text { city's GDP }\end{array}$ & $\%$ & 0.0096 & + & l \\
\hline & & $\begin{array}{l}\text { C3 Growth rate of added value of cultural } \\
\text { and creative industries }\end{array}$ & $\%$ & 0.0099 & + & $\begin{array}{c}\text { Shenzhen Statistical } \\
\text { Yearbook }\end{array}$ \\
\hline & & $\begin{array}{l}\text { C4 Total import and export of high-tech } \\
\text { products }\end{array}$ & 0.1 billion dollars & 0.0071 & + & $\begin{array}{c}\text { Shenzhen Statistical } \\
\text { Yearbook }\end{array}$ \\
\hline & & $\begin{array}{l}\text { C5 Number of cultural and creative } \\
\text { industrial parks (bases) }\end{array}$ & l & 0.0071 & + & $\begin{array}{l}\text { Yearbook of Shenzhen } \\
\text { Cultural Industry }\end{array}$ \\
\hline & & $\begin{array}{l}\text { C6 The number of scaled units of science and } \\
\text { technology in industrial enterprises }\end{array}$ & l & 0.0117 & + & $\begin{array}{c}\text { Shenzhen Statistical } \\
\text { Yearbook }\end{array}$ \\
\hline & & C7 Number of performing groups & I & 0.0129 & + & $\begin{array}{l}\text { Guangdong Statistical } \\
\text { Yearbook }\end{array}$ \\
\hline & Factors & C8 Number of Cultural Centers & I & 0.0093 & + & $\begin{array}{l}\text { Guangdong Statistical } \\
\text { Yearbook }\end{array}$ \\
\hline & & C9 Number of public libraries & I & 0.0105 & + & $\begin{array}{l}\text { Guangdong Statistical } \\
\text { Yearbook }\end{array}$ \\
\hline \multirow{11}{*}{$\begin{array}{l}\text { Cultural and } \\
\text { creative } \\
\text { industry } \\
\text { system }(\mathrm{C})\end{array}$} & & $\begin{array}{l}\text { C10 Number of museums (including art } \\
\text { galleries) }\end{array}$ & l & 0.0113 & + & $\begin{array}{l}\text { Guangdong Statistical } \\
\text { Yearbook }\end{array}$ \\
\hline & Employees & $\begin{array}{l}\text { C11 The number of employees in cultural } \\
\text { institutions }\end{array}$ & I & 0.0112 & + & $\begin{array}{l}\text { Guangdong Statistical } \\
\text { Yearbook }\end{array}$ \\
\hline & & C12 R\&D employees & l & 0.0072 & + & $\begin{array}{c}\text { Shenzhen Statistical } \\
\text { Yearbook }\end{array}$ \\
\hline & Innovation & C13 R\&D expentidure & 0.1 billion yuan & 0.0088 & + & $\begin{array}{c}\text { Shenzhen Statistical } \\
\text { Yearbook }\end{array}$ \\
\hline & investment & C14 Government R\&D spending & 0.1 billion yuan & 0.0101 & + & $\begin{array}{c}\text { Shenzhen Statistical } \\
\text { Yearbook }\end{array}$ \\
\hline & & $\begin{array}{l}\text { C15 The proportion of government } \mathrm{R} \& \mathrm{D} \\
\text { expenditure in the city's whole GDP }\end{array}$ & $\%$ & 0.0074 & + & I \\
\hline & & $\begin{array}{l}\text { C16 Ownership of authorized patents at the } \\
\text { end of the year }\end{array}$ & set & 0.0082 & + & $\begin{array}{c}\text { Shenzhen Statistical } \\
\text { Yearbook }\end{array}$ \\
\hline & Innovation output & & & & & Shenzhen White Book on \\
\hline & & C17 Patents per 10,000 people & set & 0.0103 & + & $\begin{array}{c}\text { Intellectual Property } \\
\text { Development }\end{array}$ \\
\hline & Innovation carrier & C18 Number of innovative carrier projects & I & 0.0106 & + & $\begin{array}{c}\text { Shenzhen Statistical } \\
\text { Yearbook }\end{array}$ \\
\hline & $\begin{array}{l}\text { Innovation } \\
\text { environment }\end{array}$ & $\begin{array}{l}\text { C19 The proportion of consumption } \\
\text { expenditure on culture and entertainment in } \\
\text { whole living expenses }\end{array}$ & $\%$ & 0.0089 & + & $\begin{array}{c}\text { Shenzhen Statistical } \\
\text { Yearbook }\end{array}$ \\
\hline \multirow{2}{*}{$\begin{array}{l}\text { Tourism } \\
\text { industry } \\
\text { system }(\mathrm{T})\end{array}$} & \multirow[t]{2}{*}{ Scales } & T1 Domestic tourism revenue & 0.1 billion yuan & 0.0740 & + & $\begin{array}{l}\text { Guangdong Statistical } \\
\text { Yearbook }\end{array}$ \\
\hline & & T2 Foreign exchange income from tourism & 0.1 billion yuan & 0.0655 & + & $\begin{array}{l}\text { Guangdong Statistical } \\
\text { Yearbook }\end{array}$ \\
\hline
\end{tabular}




\section{Continued}

\begin{tabular}{|c|c|c|c|c|c|}
\hline & T3 Tourism revenue & 0.1 billion yuan & 0.0717 & + & $\begin{array}{l}\text { Guangdong Statistical } \\
\text { Yearbook }\end{array}$ \\
\hline & $\begin{array}{l}\text { T4 The total income of tourism accounts for } \\
\text { the proportion of the city's GDP }\end{array}$ & $\%$ & 0.0688 & + & I \\
\hline & $\begin{array}{l}\text { T5 The total income of tourism accounts for } \\
\text { the proportion of the city's output value }\end{array}$ & $\%$ & 0.0466 & + & I \\
\hline & T6 Domestic tourists & I & 0.0687 & + & $\begin{array}{c}\text { Shenzhen Statistical } \\
\text { Yearbook }\end{array}$ \\
\hline & T7 Number of inbound tourists & I & 0.0658 & + & $\begin{array}{c}\text { Shenzhen Statistical } \\
\text { Yearbook }\end{array}$ \\
\hline \multirow{3}{*}{ Factors } & T8 Number of star hotels & l & 0.0591 & + & $\begin{array}{c}\text { Shenzhen Statistical } \\
\text { Yearbook }\end{array}$ \\
\hline & T9 Number of travel agencies & I & 0.0737 & + & $\begin{array}{l}\text { Directory of Guangdong } \\
\quad \text { Travel Agencies }\end{array}$ \\
\hline & T10 Number of A-grade scenic spots & l & 0.0625 & + & $\begin{array}{c}\text { Shenzhen Government } \\
\text { Website }\end{array}$ \\
\hline \multirow{3}{*}{ Employees } & T11 Number of hotel employees & l & 0.0482 & + & $\begin{array}{c}\text { Shenzhen Statistical } \\
\text { Yearbook }\end{array}$ \\
\hline & T12 Number of travel agency employees & I & 0.0585 & + & $\begin{array}{c}\text { Shenzhen Statistical } \\
\text { Yearbook }\end{array}$ \\
\hline & T13 Number of employees of the scenic spots & l & 0.0305 & + & $\begin{array}{c}\text { Shenzhen Statistical } \\
\text { Yearbook }\end{array}$ \\
\hline \multirow{3}{*}{$\begin{array}{l}\text { Operating } \\
\text { condition }\end{array}$} & T14 Hotels' revenue & Ten thousand yuan & 0.0657 & + & $\begin{array}{c}\text { Shenzhen Statistical } \\
\text { Yearbook }\end{array}$ \\
\hline & T15 Travel agencies' revenue & Ten thousand yuan & 0.0612 & + & $\begin{array}{c}\text { Shenzhen Statistical } \\
\text { Yearbook }\end{array}$ \\
\hline & T16 The income of scenic areas & Ten thousand yuan & 0.0794 & + & $\begin{array}{c}\text { Shenzhen Statistical } \\
\text { Yearbook }\end{array}$ \\
\hline
\end{tabular}

Note: “+" means positive index, “-” is negative index.

1) Adopt the method of extremization to standardize the original data. However, "0" may appear after the standardization. In order to make the data still meaningful after the standardization, this paper will conduct the non-negative processing to the data after the standardization, and add 1 [33]. Finally, the standardized value is $x_{i j}^{\prime}$.

$$
x_{i j}^{\prime}= \begin{cases}\frac{x_{i j}-\min \left(x_{i j}\right)}{\max \left(x_{i j}\right)-\min \left(x_{i j}\right)}+1 & \left(x_{i j}^{\prime} \text { is positive index }\right) \\ \frac{\max \left(x_{i j}\right)-x_{i j}}{\max \left(x_{i j}\right)-\min \left(x_{i j}\right)}+1 \quad\left(x_{i j}^{\prime} \text { is negative index }\right)\end{cases}
$$

2) Make specific gravity transformation to the index.

$$
s_{i j}=\frac{x_{i j}^{\prime}}{\sum_{i=1}^{m} x_{i j}^{\prime}}
$$


3) Calculate the entropy value of the index $j$.

$$
h_{j}=-\frac{1}{\ln m} \sum_{i=1}^{m}\left(s_{i j} \times \ln s_{i j}\right)
$$

4) Calculate the difference degree of index $j$.

$$
\alpha_{j}=1-h_{j}
$$

5) Calculate the weight of the index.

$$
w_{j}=\frac{\alpha_{j}}{\sum_{j=1}^{n} \alpha_{j}}
$$

The linear weighting method is used to determine the comprehensive evaluation value of the two systems [30]. Among them, $U_{1}$ and $U_{2}$ respectively represent the comprehensive evaluation function of the two systems. $u_{i j}$ represents the efficiency coefficient, which is the data after the standardizing the original data. The higher the value is, the higher the industrial development satisfaction is [30]. $u_{i j}$ is similar to the standardization process of $x_{i j}^{\prime}$. $u_{i j}$ doesn't have to shift one unit to the right, because its value range is $[0,1]$. The calculation formula is as follows:

$$
u_{i j}=\left\{\begin{array}{cc}
\frac{x_{i j}-\min \left(x_{i j}\right)}{\max \left(x_{i j}\right)-\min \left(x_{i j}\right)} & \left(u_{i j} \text { is positive index }\right) \\
\frac{\max \left(x_{i j}\right)-x_{i j}}{\max \left(x_{i j}\right)-\min \left(x_{i j}\right)} & \left(u_{i j} \text { is negative index }\right)
\end{array}\right.
$$

\subsubsection{Evaluation Method of Coupled Coordinative Degree}

With reference to the existing research methods, a coupled and coordinative degree model reflecting the coordinative development of cultural and creative industry and tourism industry is constructed. Where, $C$ is the coupled degree of the two systems, and the value range is $[0,1]$. The higher the $C$ value of the coupled degree is, the higher the coupled degree is, indicating that the cultural and creative industry system is more closely related to the tourism industry system, and the system tends to be orderly. $D$ is the coupled and coordinative degree of the two systems, which can reflect the coordination relationship and development level between the cultural, cultural and creative industry system and the tourism industry system [34]. $T$ is the comprehensive coordinative index of the cultural and creative industry system and the tourism industry system, reflecting the contribution of the overall development level of the two systems to the coordinative degree. $a$ and $b$ are specific weights by considering that cultural and creative industry and tourism industry complement each other and have the same importance, thus this paper sets both $a$ and $b 0.5$. At the same time, in order to directly reflect the coupled coordinative development of cultural and creative industry and tourism industry, this paper refers to previous research results (Table 3) 
Table 3. Discriminating standard of coordinated coupling of cultural and creative industry and tourism industry.

\begin{tabular}{cccc}
\hline $\begin{array}{c}\text { Coordination } \\
\text { degree } D\end{array}$ & Coordination grade & $\begin{array}{c}\text { Coordination } \\
\text { degree } D\end{array}$ & Coordination grade \\
\hline $0.0000-0.10$ & Extreme imbalance & $0.5001-0.60$ & Barely coordinated \\
$0.1001-0.20$ & Severe imbalance & $0.6001-0.70$ & Primary coordination \\
$0.2001-0.30$ & Moderate imbalance & $0.7001-0.80$ & Intermediate coordination \\
$0.3001-0.40$ & Mild imbalance & $0.8001-0.90$ & Favorable coordination \\
$0.4001-0.50$ & On the verge of imbalance & $0.9001-1.00$ & Superior coordination \\
\hline
\end{tabular}

[35], and grades the coupled and coordinative degree according to certain standards.

The calculation formula of coupled degree $C$ is as follows [36]:

$$
C=2 \sqrt{\frac{U_{1} \times U_{2}}{\left(U_{1}+U_{2}\right)^{2}}}
$$

The calculation formula of coupled and coordinative degree $D$ is as follows [36]:

$$
\begin{aligned}
& D=\sqrt{C \times T} \\
& T=a U_{1}+b U_{2}
\end{aligned}
$$

\subsection{Data Sources}

This study mainly collected data from Shenzhen Statistical Yearbook and Guangdong Statistical Yearbook from 2009 to 2018, and supplemented them with relevant data from Shenzhen Government Website, Shenzhen White Book on Intellectual Property Development and Shenzhen Cultural Industry Yearbook. In order to show the data source of each indicator clearly, this paper has made some labels in Table 2. Besides, due to the absence of some years' data, this paper adopts interpolation method to make up the data according to the average growth rate of year data or the trend of change in recent years.

\section{Data Analysis}

According to the coupling evaluation model in this paper, the comprehensive evaluation value of the cultural creative industry and tourism industry in Shenzhen during 2008-2017, as well as the coupled degree and coupled coordinative degree between the two systems are calculated respectively (Table 4). At the same time, the grey correlation model is introduced to explore the primary driving factors of the coupled and coordinative development of the two industries.

\subsection{Development of Shenzhen's Cultural and Creative Industry and Tourism Industry}

According to Table 4 and Figure 2, as well as the comprehensive evaluation 
Table 4. Coupling and coordination degree and evaluation of Shenzhen cultural and creative industry and tourism industry (2008-2017).

\begin{tabular}{|c|c|c|c|c|c|c|}
\hline Year & $U_{1}$ & $U_{2}$ & $U_{1}$ vs $U_{2}$ & $C$ & $D$ & Coordination grade \\
\hline 2008 & 0.0341 & 0.1831 & Cultural and creative industry development lagged & 0.7276 & 0.2811 & Moderate imbalance \\
\hline 2009 & 0.0909 & 0.1902 & Cultural and creative industry development lagged & 0.9355 & 0.3626 & Mild imbalance \\
\hline 2010 & 0.1788 & 0.2957 & Cultural and creative industry development lagged & 0.9692 & 0.4795 & On the verge of imbalance \\
\hline 2011 & 0.2742 & 0.4062 & Cultural and creative industry development lagged & 0.9810 & 0.5777 & Barely coordinated \\
\hline 2012 & 0.3954 & 0.4893 & Cultural and creative industry development lagged & 0.9944 & 0.6632 & Primary coordination \\
\hline 2013 & 0.5293 & 0.5858 & Cultural and creative industry development lagged & 0.9987 & 0.7462 & Intermediate coordination \\
\hline 2014 & 0.6220 & 0.6821 & Cultural and creative industry development lagged & 0.9989 & 0.8071 & Favorable coordination \\
\hline 2015 & 0.7298 & 0.7935 & Cultural and creative industry development lagged & 0.9991 & 0.8723 & Favorable coordination \\
\hline 2016 & 0.8354 & 0.7446 & Tourism industry development lagged & 0.9983 & 0.8881 & Favorable coordination \\
\hline 2017 & 0.9726 & 0.6639 & Tourism industry development lagged & 0.9820 & 0.8964 & Favorable coordination \\
\hline
\end{tabular}

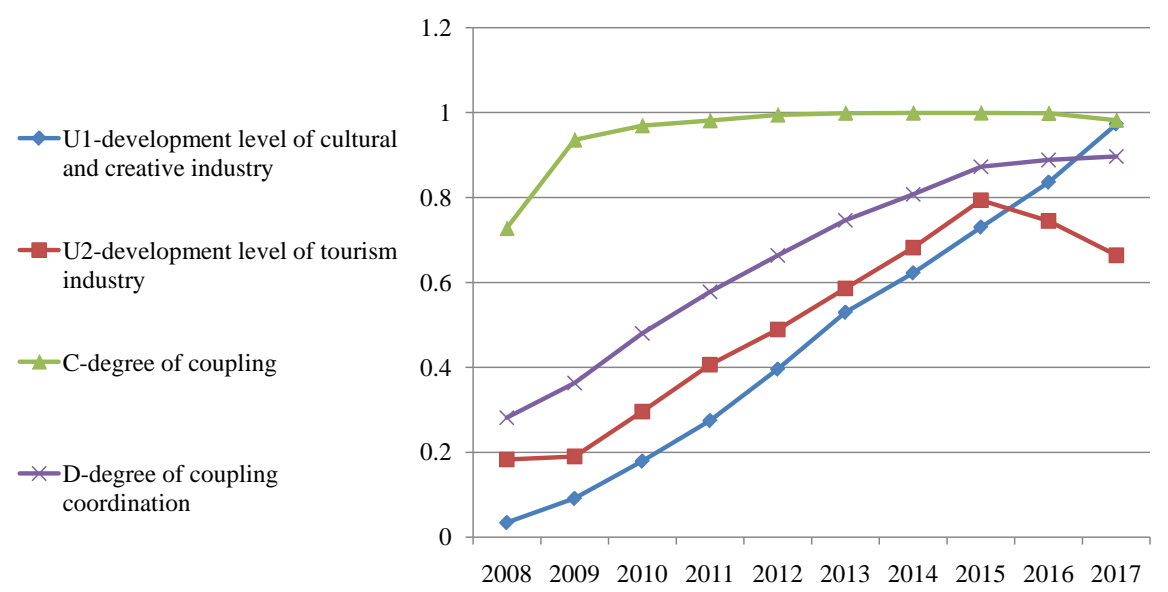

Figure 2. Comparison of the development levels of cultural and creative industry and tourism industry and coupling degree and coordination degree.

value of Shenzhen's cultural and creative industry and tourism industry systems, the comprehensive development level of the two industries showed a rapid rise from 2008 to 2017, indicating that the overall development of the two industries was good in the past decade. In terms of the tourism industry system, from 2008 to 2015 , it was increasing year by year, but from 2016 to 2017, decreasing. According to their different comprehensive development levels, the comprehensive development levels from 2008 to 2017 can be divided into three types [30]. When $U_{1}=U_{2}$, they develop synchronously; when $U_{1}<U_{2}$, cultural and creative industry lags behind. Table 4 shows that during 2008-2015, as for the coupled and coordinative degree, cultural creative industry is lagged behind, that is, the comprehensive development level of tourism industry is higher than that of cultural creative industry, but in 2016, tourism industry decreased and overtaken by cultural creative industry. The possible reason for such a decline in 2016-2017 is that the tourism industry in Shenzhen was facing new challenges. On the one 
hand, its carrying capacity is limited, and the construction area for tourism projects is scarce, leading to the lack of sustainable development; on the other hand, the product structure tends to be aging, affecting the market competitiveness of core tourism products [37], which further shows that the cultural and creative industry has not provided enough support to the tourism industry in 2016-2017, and even restricted its the development. Therefore, under the background of cultural and tourism integration, the innovation of the cultural and creative industry should be introduced into the tourism industry to promote its upgrading and transformation.

\subsection{Coupled and Coordinative Degree of Cultural and Creative Industry and Tourism Industry in Shenzhen}

As can be seen from Table 4 and Figure 2, the coupling value of cultural and creative industry and tourism industry in Shenzhen from 2008 to 2017 was between 0.70 and 0.99 , with an average value of 0.9585 , indicating a strong interaction between the two industries. From 2008 to 2009, the coupled degree surged from 0.7276 to 0.9355 . After 2009, the growth slowed down and maintained a high level of development. From 2008 to 2017, the coupled and coordinative degree between the cultural and creative industries and the tourism industry in Shenzhen improved steadily, and it changed from imbalance to coordination. As a whole, it can be divided into two stages: the first is the imbalance stage from 2008 to 2010, and the second is the coordination stage from 2011 to 2017, which shows that before 2010, the interaction and coordination between the two were weak and the interaction between them was not strong. Since 2011, the coupled interaction effect between the two has been gradually enhanced. Moreover, the coordinative degree of the two industries has reached a high level from ordinary to good in 2014. It is because that in 2010, Shenzhen Municipal Party Committee and Municipal Government forged the cultural creative industry the fourth largest strategic emerging industry, and in 2011, they promulgated the Plan of Shenzhen Cultural and Creative Industry Revitalization (2011-2015), which greatly stimulates its development and promotes deep integrated development of the two industries.

\subsection{Analysis of Grey Correlation}

Shenzhen is a typical city that conducts study on the coupled and coordinative development of cultural and creative industry and tourism industry. On the one hand, it is a "city of creativity" with international influence and obvious advantages in cultural and creative industry; also, it is a national model area for tourism and one of the world's top 10 most popular tourist destinations [38]. However, as of 2017, the coupled and coordinative degree of the two system in Shenzhen still remained at just a good level, which has not yet reached the ideal state of high-quality coordination (Table 4). Moreover, it can be seen from Figure 2 that the overall development level of the tourism industry was poorly developed and has declined in 2016-2017. Therefore, how to effectively revitalize 
the tourism industry has become an urgent problem to be solved.

Based on the above, in order to formulate effective countermeasures, this paper introduces the grey correlation degree model to explore the relational degree of two systems and internal indicators. The coupled and coordinative model reveals the interaction between subsystems, while the grey relational model focuses on exploring the relationship between indicators and the system, or between indicators, which can deeply reveal the internal relationship of the system.

First of all, in order to screen out the key driving force index that affects the coupled and coordinative degree to the high-quality coordination, this paper takes the coupled and coordinative degree between the two industries as the reference sequence $X_{0}$, and compares the comprehensive evaluation value as the sequence $X_{1 i}$ and $X_{2 i}$ respectively. $X_{0}, X_{1 i}$ and $X_{2 i}$ are all composed of standardized data by using $\mathrm{z}$-score method [39]. $p$ is the resolution coefficient, which is generally 0.5 [30]. The value range of correlation degree $R_{j}$ is [0,1], which reflects the correlation strength of reference and comparison sequence. The closer $R_{j}$ value is to 1 , the higher the correlation between the two is. The calculation formulas of grey correlation coefficient $Y_{j}(k)$ and grey correlation degree $R_{j}$ are as follows [40]:

$$
\begin{gathered}
Y_{j}(k)=\frac{\min _{j} \min _{k}\left|X_{0}(k)-X_{j}(k)\right|+p \max _{j} \max _{k}\left|X_{0}(k)-X_{j}(k)\right|}{\left|X_{0}(k)-X_{j}(k)\right|+p \max _{j} \max _{k}\left|X_{0}(k)-X_{j}(k)\right|} \\
R_{j}=\frac{1}{m} \sum_{k=1}^{m} Y_{j}(k) \\
k=1,2,3, \cdots, m ; j=1,2,3, \cdots, n .
\end{gathered}
$$

Calculation results show that the index which has strong coupled and coordinative degree is $\mathrm{C} 2$ proportion of added value of cultural and creative industry accounting for the city's GDP > C5 number of cultural and creative industrial park (base) $>$ C8 number of cultural centers $>$ C11 number of employees in culture or cultural relics $>\mathrm{C} 1$ the added value of cultural and creative industry $>$ C17 owned patents per ten thousand people (Table 5). The above six secondary indexes are subordinate to the primary indicators: industrial scale, industrial factors, practitioners and innovation output. Among them, industrial scale has the greatest impact on the evolution of the coupled and coordinative degree of the two industries, followed by industrial factors, practitioners and innovation output. In order to promote the coupled and coordinative development of the two industries, Shenzhen should continue to expand the scale of the cultural and creative industry and improve its development. At the same time, the cultivation efforts to cultural and creative industrial parks (bases) should be made, and the construction of cultural centers and free services for the public should be improved. Shenzhen should also strengthen the construction of employees in cultural and creative industries from the aspects of both quantity and quality. On the one hand, innovation and patent application should be encouraged to increase the number and expand the types. On the other hand, from the management 
Table 5. The grey correlation ranking of cultural and creative industry, tourism industry and coupling coordination.

\begin{tabular}{|c|c|c|c|c|}
\hline System & Primary index & Secondary index & Correlation degree $R_{j}$ & Ranking \\
\hline \multirow{19}{*}{$\begin{array}{l}\text { Cultural and creative } \\
\text { industry system }(\mathrm{C})\end{array}$} & \multirow{4}{*}{ Scales } & $\mathrm{C} 1$ Added value of cultural and creative industry & 0.8748 & 5 \\
\hline & & $\begin{array}{l}\text { C2 Added value of cultural and creative industries accounts for the } \\
\text { proportion of the city's GDP }\end{array}$ & 0.9515 & 1 \\
\hline & & C3 Growth rate of added value of cultural and creative industries & 0.4904 & 19 \\
\hline & & C4 Total import and export of high-tech products & 0.7795 & 14 \\
\hline & \multirow{6}{*}{ Factors } & C5 Number of cultural and creative industrial parks (bases) & 0.8888 & 2 \\
\hline & & $\begin{array}{l}\text { C6 The number of scaled units of science and technology in } \\
\text { industrial enterprises }\end{array}$ & 0.5424 & 17 \\
\hline & & C7 Number of performing groups & 0.4940 & 18 \\
\hline & & C8 Number of Cultural Centers & 0.8829 & 3 \\
\hline & & C9 Number of public libraries & 0.8390 & 11 \\
\hline & & C10 Number of museums (including art galleries) & 0.8477 & 10 \\
\hline & Employees & C11 The number of employees in cultural institutions & 0.8749 & 4 \\
\hline & \multirow{4}{*}{$\begin{array}{l}\text { Innovation } \\
\text { investment }\end{array}$} & C12 R\&D employees & 0.8162 & 12 \\
\hline & & C13 R\&D expentidure & 0.8595 & 7 \\
\hline & & C14 Government R\&D spending & 0.7881 & 13 \\
\hline & & $\begin{array}{l}\text { C15 The proportion of government R\&D expenditure in the city's } \\
\text { whole GDP }\end{array}$ & 0.7300 & 16 \\
\hline & \multirow{2}{*}{ Innovation output } & C16 Ownership of authorized patents at the end of the year & 0.8579 & 8 \\
\hline & & C17 Patents per 10,000 people & 0.8688 & 6 \\
\hline & Innovation carrier & C18 Number of innovative carrier projects & 0.8491 & 9 \\
\hline & $\begin{array}{l}\text { Innovation } \\
\text { environment }\end{array}$ & $\begin{array}{l}\text { C19 The proportion of consumption expenditure on culture and } \\
\text { entertainment in whole living expense }\end{array}$ & 0.7614 & 15 \\
\hline \multirow{16}{*}{$\begin{array}{l}\text { Tourism industry } \\
\text { system }(\mathrm{T})\end{array}$} & \multirow{7}{*}{ Scales } & T1 Domestic tourism revenue & 0.8770 & 8 \\
\hline & & T2 Foreign exchange income from tourism & 0.9325 & 1 \\
\hline & & T3 Tourism revenue & 0.8882 & 7 \\
\hline & & $\begin{array}{l}\text { T4 The total income of tourism accounts for the proportion of the } \\
\text { city's GDP }\end{array}$ & 0.7542 & 12 \\
\hline & & $\begin{array}{l}\text { T5 The total income of tourism accounts for the proportion of the } \\
\text { city's output value }\end{array}$ & 0.6276 & 14 \\
\hline & & T6 Domestic tourists & 0.9080 & 5 \\
\hline & & T7 Number of inbound tourists & 0.8745 & 9 \\
\hline & \multirow{3}{*}{ Factors } & T8 Number of star hotels & 0.6020 & 16 \\
\hline & & T9 Number of travel agencies & 0.9040 & 6 \\
\hline & & T10 Number of A-grade scenic spots & 0.9236 & 3 \\
\hline & \multirow{3}{*}{ Employees } & T11 Number of hotel employees & 0.6188 & 15 \\
\hline & & T12 Number of travel agency employees & 0.9185 & 4 \\
\hline & & T13 Number of employees of the scenic spots & 0.6896 & 13 \\
\hline & \multirow{3}{*}{ Operating condition } & T14 Hotels' revenue & 0.8710 & 10 \\
\hline & & T15 Travel agencies' revenue & 0.9250 & 2 \\
\hline & & T16 The income of scenic areas & 0.8582 & 11 \\
\hline
\end{tabular}


system and laws and regulations to improve the protection and development of patents and other intellectual property rights; moreover, the conversion rate of patents should be improved by combining patents with industrial practices to promote the interactive and coordinative development of the two industries.

The index with strong correlation is $\mathrm{T} 2$ tourism foreign exchange income $>$ T15 travel agency income $>$ T10A number of scenic spots $>$ T12 number of travel agency employees $>\mathrm{T} 6$ domestic tourists $>\mathrm{T} 9$ number of travel agencies (Table 5). The above six secondary indexes are subordinate to the primary indexes: industrial scale, industrial factors, operation conditions and employees. Among them, industrial scale has the greatest influence on the evolution of the coupled and coordinative degree of the two industries, followed by industrial factors, operation conditions and employees. To in-depth analyze constraints that have impact on the overall development of the tourism industry in 2016-2017, by using grey correlation analysis method, its comprehensive evaluation value is a reference sequence, and the secondary index comprehensive evaluation value is comparative sequence, through analyzing grey correlation degree between system and index to analyze the dynamic effect and restriction to various indexes of development of the tourism industry system. Calculation results found that from the tourism industry system, the indexes affecting the "Shenzhen's coupled and coordinative degree of the two systems" and "Shenzhen's development level of tourism industry system" are foreign exchange income of tourism, travel agencies operation revenue, the number of A-grade scenic spots, the number of travel agency staff, number of domestic tourists and travel agencies (Table 5 \& Table 6). Among them, foreign exchange income of tourism is most closely related, followed by the operation income of travel agencies and the number of A grade scenic spots, which indicates that they have a strong influence on the evolution of coupled and coordinative degree and the development of tourism industry. Shenzhen, because of its unique natural geographical advantages and temperament, ranked the tenth world's most popular tourist destination [38], attracting a large number of foreign tourists each year [41], its tourism foreign exchange income plays a pivotal role to tourism development of Shenzhen. Travel agencies, as one of the platforms providing inbound tourism services [42], also directly affect its foreign exchange income. In order to promote the coupled and coordinative development, and enhance the vitality of Shenzhen's tourism industry, the foreign exchange income of tourism should be consolidated, also, the government should optimize the inbound tourism environment, and continue to make efforts in visa, shopping tax rebate, document facilitation and other aspects; travel agents and the scenic areas should be strengthened in management by considering the integrated development to add culture creative elements, widen travel upstream and downstream industry chain, innovate culture experience activity, so as to enhance attraction for foreign tourists, stimulate tourism industry development, and make the two industries high-quality coordination. 
Table 6. The grey correlation ranking of tourism industry system and its secondary indexes.

\begin{tabular}{|c|c|c|c|c|}
\hline System & Primary index & Secondary index & Correlation degree $R_{j}$ & Ranking \\
\hline \multirow{16}{*}{$\begin{array}{l}\text { Tourism industry } \\
\text { system (T) }\end{array}$} & \multirow{7}{*}{ Scales } & T1 Domestic tourism revenue & 0.8676 & 8 \\
\hline & & T2 Foreign exchange income from tourism & 0.9184 & 1 \\
\hline & & T3 Tourism revenue & 0.8806 & 7 \\
\hline & & $\begin{array}{l}\text { T4 The total income of tourism accounts for the proportion of the } \\
\text { city's GDP }\end{array}$ & 0.7677 & 12 \\
\hline & & $\begin{array}{l}\text { T5 The total income of tourism accounts for the proportion of the } \\
\text { city's output value }\end{array}$ & 0.6039 & 14 \\
\hline & & T6 Domestic tourists & 0.9005 & 5 \\
\hline & & T7 Number of inbound tourists & 0.8377 & 11 \\
\hline & \multirow{3}{*}{ Factors } & T8 Number of star hotels & 0.5853 & 16 \\
\hline & & T9 Number of travel agencies & 0.8985 & 6 \\
\hline & & T10 Number of A-grade scenic spots & 0.9022 & 4 \\
\hline & \multirow{3}{*}{ Employees } & T11 Number of hotel employees & 0.5948 & 15 \\
\hline & & T12 Number of travel agency employees & 0.9070 & 3 \\
\hline & & T13 Number of employees of the scenic spots & 0.6654 & 13 \\
\hline & \multirow{3}{*}{ Operating condition } & T14 Hotels' revenue & 0.8646 & 9 \\
\hline & & T15 Travel agencies' revenue & 0.9113 & 2 \\
\hline & & T16 The income of scenic areas & 0.8600 & 10 \\
\hline
\end{tabular}

\section{Conclusion}

Under the background of the coupled development, this article combed the coupled and coordinative mechanism of the cultural and creative industries and tourism industry, by taking Shenzhen as the empirical case, using the coupled and coordinative degree model to analyze coupled and coordinative development from 2008 to 2017. At the same time, the paper introduces a grey correlation model to explore the driving force that promotes the coupled and coordinative development of two industries. The findings are as follows:

1) Coupled and coordinative mechanism with the purpose of interactive and coupled development of cultural creative industry and tourism industry, cultural and creative industry provides creative concepts for tourism industry, tourism industry provides platform support for cultural creative industry is as follows: in terms of economy, cultural and creative industry promotes transformation and upgrading of the tourism industry and its growth, while tourism expands the market by extending the creativity; in terms of culture, the cultural and creative industry provides technical support and cultural creativity for the tourism industry, while the tourism industry can effectively protect and pass on and promote the exchange of cultural creativity.

2) Overall, the comprehensive development level of the cultural and creative industry and the tourism industry in Shenzhen increased rapidly from 2008 to 
2017, and the two industries developed well except that the comprehensive evaluation value of the tourism industry declined from 2016 to 2017 and was overtaken by the cultural and creative industry. In addition, according to the comprehensive development level, industrial developmental types are divided: from 2008 to 2015, the development of cultural and creative industries lagged behind; from 2016 to 2017, it was tourism industry.

3) The results of the coupled and coordinative model show that there is a significant coupled development relationship between the two industries, but there is still room for improvement of the coupled coordination. From 2008 to 2017, the interaction was strong with coupling value distributing between 0.70 and 0.99, mean value of 0.9585 . From 2008 to 2017, the coupled and coordinative degree improved steadily and changed from imbalance to coordination. From 2008 to 2010, it was in the imbalance, while from 2011 to 2017, it was in the coordination, among which, from 2014 to 2017, it was in a good coordination without ideal quality.

4) The grey correlation calculation results show that the index which has strong coupled and coordinative degree is C2 proportion of added value of cultural and creative industry accounting for the city's GDP > C5 number of cultural and creative industrial park (base) $>$ C8 number of cultural centers $>\mathrm{C} 11$ number of employees in culture or cultural relics $>\mathrm{C} 1$ the added value of cultural and creative industry $>\mathrm{C} 17$ owned patents per ten thousand people, from the tourism industry system, the indexes affecting the "Shenzhen's coupled and coordinative degree of the two systems" and "Shenzhen's development level of tourism industry system" are foreign exchange income of tourism, travel agencies operation revenue, the number of A-grade scenic spots, the number of travel agency staff, number of domestic tourists and travel agencies. Among them, foreign exchange income of tourism is most closely related, followed by the operation income of travel agencies and the number of A-grade scenic spots and domestic tourists. In the future, Shenzhen should promote the coupled and coordinative development of the two industries by expanding the scale, increasing the input of industrial elements, strengthening the construction of the workforce, encouraging innovation and patent application.

\section{Discussion}

This paper, to some extent, enriches the research system of cultural and tourism integration, which is of referential significance to the policy research of promoting the coordinated development of cultural and creative industry and tourism industry in Shenzhen. However, this paper carries out research based on the background of cultural and tourism integration, which includes system integration, product integration, industrial integration, market integration, and spatial integration, etc. [43]. This study is not comprehensive and profound from the perspective of industrial integration, more perspectives are expected. In addition, this paper focuses on the analysis of time series of the city, and lacks a 
comparison of the differences of other spatial regions. Shenzhen, where the economy is prosperous and developed, has highly developed the cultural and creative industry and tourism industry, so this paper is of poor reference to the regions with that low development levels. Moreover, it is limited by data availability, on the one hand, the selected indicators are difficult to fully reflect the characteristics of the two industries, on the other hand, on the basis of historical data average or trend in recent years, the interpolation method is used to supplement the missing data, so the selected data cannot completely and objectively reflect its coupled and coordinative development.

\section{Conflicts of Interest}

The authors declare no conflicts of interest regarding the publication of this paper.

\section{References}

[1] Zou, Y. (2017) Fusion Development of Tourism and Cultural Creative Industry Mechanism-Taking Sichuan Chengdu as Example. Reformation \& Strategy, 33, $126-128+132$.

[2] Gao, E.D. and Xie, H.Z. (2016) Research on Regional Culture Creative Industry and Tourism and Related Industry Integration Development-A Case Study of Xishan District of Kunming. Tourism Research, 8, 74-79.

[3] Xu, A.P. and Yu, G.L. (2018) Development Strategy of Tianjin Cultural and Creative Industries from the Perspective of Beijing-Tianjin-Hebei Cooperative Development. City, 31, 3-9.

[4] Culture, Sports and Tourism Administration of Shenzhen Municipality (2011) Shenzhen Cultural and Creative Industry Revitalization Development Plan.

[5] National Bureau of Statistics of China (2018) Classification of Culture and Related Industries.

[6] Rong, Y.M. (2004) Beyond Cultural Industry: Essence and Characteristics of Creative Industry. Studies on Mao Zedong and Deng Xiaoping Theories, 11, 18-24.

[7] Liu, Y.J., Hu, L.M. and Zhou, R.X. (2009) The Interaction and Coupled Evolution between Creative Industries and Urban Development. China Soft Science Magazine, 24, 151-158.

[8] Zhang, Y.F. and Zhu, H.Y. (2012) Regional Differences Research on Coupling Development of the Cultural Industries and Tourism Industry-Based on Empirical Research though Provincial Panel Data. East China Economic Management, 26, 54-59.

[9] Zhou, Y. (2014) Coupling Development of Jiangxi Cultural Industry and Tourism Industry Based on Grey System Theory. Jiangxi Social Sciences, 34, 41-45.

[10] Fang, Z. and Zhang, H.R. (2018) Studies on Coupling Development between Cultural Industries and Tourism Industry in Fujian Province. Journal of Fujian Normal University (Philosophy and Social Sciences Edition), 63, 39-45 + 169.

[11] Fan, H.Y. and Xue, B.Q. (2016) Empirical Study on Coupling Coordination of Tourism Industry and Cultural Industry in Henan Province. Areal Research and Development, 35, 104-109.

[12] Tang, Y.J., Wang, X. and Zhang, L.L. (2015) A Study on the Evolution of the Tour- 
ism Function of the Cultural and Creative Industry Clusters in Beijing. Journal of Beijing International Studies University, 37, 27-33.

[13] Zhang, J. (2009) Study on the Integration Situation and Measures of Creative Industry and Tourism Industry in Metropolis. Tourism Forum, 2, 76-81.

[14] Yuan, J. and Zhang, M. (2016) Regional Comparison of Integration Effect between Cultural and Creative Industry Parks and Tourism Industry. World Regional Studies, 25, 119-127 + 147 .

[15] Cao, L.W. (2008) Thoughts on the Study of Industrial Coupling under the Overall Planning of Urban and Rural Areas. China Urban Planning Association, Beijing, $1685-1692$.

[16] Li, M.Y. (2008) On the Industrial Convergence and Interactive Development of Tourism Attractions Industry and Cartoon Industry. Tourism Tribune, 23, 56-62.

[17] Zhang, Y.F. and Zhu, H.Y. (2014) Empirical Research on Coupling Coordination of Cultural Performance and Tourist Flow in Southwest China. Economic Geography, 34, 182-187.

[18] Kole, S.K. (2010) Dance, Representation, and Politics of Bodies: “Thick Description" of Tahitian Dance in Hawaiian Tourism Industry. Journal of Tourism and Cultural Chance, 8, 183-205. https://doi.org/10.1080/14766825.2010.515989

[19] Connell, J. (2012) Film Tourism-Evolution, Progress and Prospects. Tourism Management, 33, 1007-1029. https://doi.org/10.1016/j.tourman.2012.02.008

[20] Lu, X.Q. (2009) On the Industrial Convergence of Online Games and Tourism. Journal of Chongqing University of Posts and Telecommunications (Social Science), 21, 42-45.

[21] Yin, Y.M. and Lu, M.Y. (2009) On the Coupled Development of Tourism Industry and Creative Industry in Ethnic Areas. Tourism Tribune, 24, 42-48.

[22] Kostopoulou, S. (2013) On the Revitalized Waterfront: Creative Milieu for Creative Tourism. Sustainability, 5, 4578-4593. https://doi.org/10.3390/su5114578

[23] Yao, D.X. (2007) The Definition and Significance of Cultural and Creative Industry. Commercial Times, 26, 95-96.

[24] Zhang, Y.F. and Zhu, H.Y. (2013) Empirical Research on Coupling Coordination of Cultural Industry and Tourism Industry in Southwest China. Areal Research and Development, 32, 16-21.

[25] Xu, Y., Tao, C.Q. and Ding, H. (2015) An Empirical Analysis on the Coupling of Regional Industry Innovation and Industry Upgrading: A Case of the Pearl River Delta Region. Science Research Management, 36, 109-117.

[26] Wang, H.M. (2015) Promoting Transformation and Upgrading of Tourism Industry with Cultural Creativity. Tourism Tribune, 30, 1-3.

[27] Information Office of Shenzhen Municipal People's Government (2019) Overview of Shenzhen. http://www.sz.gov.cn/cn/zjsz/gl/content/post 1377433.html

[28] Zhang, H.Y. (2018) Shenzhen Strides to Pioneer City of Cultural and Creative Industry. China Reform Daily.

[29] Culture, Sports and Tourism Administration of Shenzhen Municipality (2019) Main Statistical Indicators of Shenzhen Tourism in 2018 (Year). http://wtl.sz.gov.cn/xxgk/qt/tzgg/201901/t20190121 15315979.htm

[30] Gong, Y. and Guo, Z.R. (2017) Empirical Analysis of Coupled Coordination Development between Tourism and Finance: A Case Study of Jiangsu Province. Tourism Tribune, 32, 74-84. 
[31] Li, G.Z. and Li, C.X. (2010) Research on the Relationship between Economic Growth and Environment Based on Entropy Method. Statistics \& Decision, 26, 107-109.

[32] Wang, Y.M. and Ma, Y.F. (2011) Analysis of Coupling Coordination between Urban Tourism Economy and Transport System Development-A Case Study of Xi'an city. Journal of Shaanxi Normal University (Natural Science Edition), 39, 86-90.

[33] Peng, B.W., Wu, Y.D., Cao, H.H., Li, S.Z. and Wang, H. (2016) Coupling Coordination Research of Tourism Industry and New Urbanization-A Case Study of Yunnan. World Regional Studies, 25, 103-114.

[34] Gao, N., Ma, Y.F., Li, T.S. and Bai, K. (2013) Study on the Coordinative Development between Tourism Industry and Urbanization Based on Coupling Model: A Case Study of Xi'an. Tourism Tribune, 28, 62-68.

[35] Liao, C.B. (1999) Quantitative Judgement and Classification System for Coordinated Development of Environment and Economy-A Case Study of the City Group in the Pearl River Delta. Tropical Geography, 20, 76-82.

[36] Tang, Z. (2015) An Integrated Approach to Evaluating the Coupling Coordination between Tourism and the Environment. Tourism Management, 46, 11-19. https://doi.org/10.1016/j.tourman.2014.06.001

[37] Culture, Sports and Tourism Administration of Shenzhen Municipality, Development and Reform Commission of Shenzhen Municipality (2016) Outline of the 13th Five-Year Plan for Shenzhen Tourism.

[38] China Daily (2018) The Most Popular Tourist City in 2018: Hong Kong Topped the List Again and Bangkok Came Second. https://language.chinadaily.com.cn/a/201812/10/WS5c0db85fa310eff30328ffa0.html

[39] Cheng, Y.Q. and Deng, J.X. (2012) The Association Analysis of Urban-Rural Coupling on the Major Grain-Producing Areas of Central Jilin Province. Economic Geography, 32, 126-130+ 145.

[40] Wang, Y.W. and Qin, H. (2014) Spatial Pattern and Change Mechanism Analysis on the Coupling and Coordinating Degree of R egional Informatization and New Industrialization in China. Economic Geography, 34, 93-100.

[41] Statistics Bureau of Shenzhen Municipality, China Commercial Industry Research Institute (2019) Analysis of Shenzhen's Inbound Tourism Data from January to February 2019: Tourism Foreign Exchange Revenue Reached 735 Million US Dollars. http://www.chipcg.com/wh/25640.html

[42] Zeng, Y.H. (2018) Cultural Experience Is a Breakthrough in the Development of Inbound Tourism in China. https://www.iyiou.com/p/74346.html

[43] Sun, J.F., Li, S.T., Ji, X.M., Qin, W.S. and Wang, F.X. (2019) Coupling Analysis and Optimization Measures of Cultural Resources Endowment and Tourism Industry in Shandong. Economic Geography, 39, 207-215. 